\title{
Comparing the effects of treatment with sildenafil and cognitive-behavioral therapy on treatment of sexual dysfunction in women: a randomized controlled clinical trial
}

\author{
Abdollah Omidi ${ }^{1}$, Afshin Ahmadvand ${ }^{2}$, Mohammad Reza Najarzadegan $^{3}$, Fateme Mehrzad ${ }^{4}$
}

${ }^{1}$ Ph.D. of Clinical Psychology, Associate Professor, Department of Psychiatry, School of Medicine, Kashan University of Medical Science, Kashan, Iran

${ }^{2}$ M.D., Psychiatrist, Associate Professor, Department of Psychiatry, School of Medicine, Kashan University of Medical Science, Kashan, Iran

${ }^{3}$ M.D., Resident of Psychiatry, Department of Psychiatry, School of Medicine, Iran University of Medical Science, Tehran, Iran

${ }^{4}$ M.D., Resident of Psychiatry, Department of Psychiatry, School of Medicine, Kashan University of Medical Science, Kashan, Iran

Type of article: Original

\begin{abstract}
Background: Sexual dysfunction in women is prevalent and common in women after menopause. Many attempts to treat patients with sexual dysfunction by cognitive-behavioral therapy (CBT) methods. But to the best of our knowledge, there has been no study that compared these two methods.

Objective: The aim of this study was to assess and compare the effects of sildenafil and cognitive-behavioral therapy on treatment of sexual dysfunction in women.

Methods: In this randomized, controlled, clinical trial, 86 women with arousal and orgasm dysfunction were surveyed. The patients were divided into two groups, i.e., sildenafil and CBT groups. The patients in the sildenafil group were treated by $50 \mathrm{mg}$ of oral sildenafil one hour before intercourse, and the other group had weekly sessions of CBT for eight weeks. Sexual dysfunctions were evaluated by the Female Sexual Function Index (FSFI), a sexual satisfaction questionnaire, and the Enrich marital satisfaction scale.

Results: The mean age of the participants was $33.14 \pm 7.34$ years. The mean scores for female sexual function index, sexual satisfaction, and the Enrich marital satisfaction scale were increased in both groups during treatment $(\mathrm{p}<0.001)$. It was found that cognitive-behavioral therapy compared to treatment with sildenafil increased all subscales, except arousal, orgasm, and lubrication.

Conclusion: Cognitive-behavioral therapy is more effective than treatment with sildenafil for improving female sexual function.

Clinical trial registration: The trial was registered at the Iranian Registry of Clinical Trials (http://www.irct.ir) with the IRCT ID: IRCT2014070318338N1.

Funding: The authors received no financial support for the research, authorship, and/or publication of this article.

Keywords: Female arousal disorder, Orgasm, Marital satisfaction, Sildenafil, Cognitive-behavioral therapy
\end{abstract}

\section{Introduction}

Female sexual dysfunction is defined as a disorder of sexual desire, arousal, or orgasm, which leads to frustration and has adverse impacts on quality of life and interpersonal relationships (1). The treatment failure rate of this dysfunction is very high, with rates in the range of $23-63 \%$ in the United States. Previous studies showed that the highest prevalence of sexual dysfunction is in the age group of postmenopausal women $(2,3)$. Sexual satisfaction is known as one of the most important factors that make it possible for couples to tolerate common problems in their lives (4). This is why researchers believe that a good marital relationship often depends on sexual satisfaction $(5,6)$.

\section{Corresponding author:}

Dr. Fateme Mehrzad, Department of Psychiatry, School of Medicine, Kashan University of Medical Science, Kashan, Iran. Tel: +98.31255549111, Email: fateme_mehrzad@yahoo.com

Received: November 22, 2015, Accepted: February 06, 2016, Published: May 2016

iThenticate screening: February 06, 2016, English editing: March 12, 2016, Quality control: April 23, 2016

(C) 2016 The Authors. This is an open access article under the terms of the Creative Commons Attribution-NonCommercialNoDerivs License, which permits use and distribution in any medium, provided the original work is properly cited, the use is non-commercial and no modifications or adaptations are made. 
According to studies, the amount of sexual activity in one person and also the number of orgasms during intercourse are associated with one's satisfaction with sex $(7,8)$. Women, who have several orgasms during sexual intercourse have more sexual satisfaction than women who have only one orgasm (9). Thus, the lack of orgasm is an important factor that contributes to sexual dissatisfaction (10). Various terms, such as compatibility, satisfaction, and complacency, are used to describe the quality of a sexual relationship $(11,12)$. As reported by Sadeghi et al., in $1997,74 \%$ of women had a tendency to divorce due to the lack of sexual satisfaction, and $61.4 \%$ of them were divorced (13). In CBT, it is believed that negative thinking about sexual activity makes its symptoms more constant and concerning, therefore it is important to discover these negative self-concepts to make a successful analysis of sexual problems (14). It is believed that sexual problems are a result of past learning and punishments, so, treatment must be focused on behavioral problems and on efforts to reconnect with them (15). Libman and colleagues investigated the role of CBT for treatment of secondary orgasmic dysfunction, and they showed a wide range of behavioral scales and inner satisfaction after CBT (16). Meston and colleagues also showed that the CBT approach is the best treatment for female orgasmic disorder (17).

Sildenafil citrate (Viagra) is an oral medication for the treatment of erectile dysfunction. This medication is a selective inhibitor of phosphodiesterase- 5 that increases the activity of cyclic guanosine monophosphate (cGMP) (18), but sildenafil currently is used for erectile dysfunction in men. Increased understanding of sexual performance in women has proven its usefulness in the treatment of sexual dysfunction in females, since this medication can cause vaginal vasodilatation and increased excitability of the vagina and clitoris, as well as enhanced lubrication (19). In a meta-analysis that surveyed the effect of sildenafil on female sexual disorders and was focused on its physiological impacts on genital congestion, the results showed that sildenafil was significantly beneficial for the treatment of female sexual dysfunction (20).

Since, to date, no research has been conducted on the effectiveness of the cognitive-behavioral approach, sildenafil has been a part of the treatment of female sexual dysfunction. Given the undeniable importance of treating this disorder, we decided to conduct this study to determine and compare the effectiveness of two methods in the treatment of sexual dysfunction in women.

\section{Material and Methods}

\subsection{Trial design}

This study was a randomized clinical trial that was conducted from January 10, 2013 to January 10, 2014. The sample size was calculated to be 83 subjects. This sample size was calculated based on the results of previous studies (17) by assuming the test power of $80 \%$ and a confidence level of $95 \%$ and using the following formula:

$\mathrm{n}=\left(\mathrm{Z}_{1-\alpha / 2}+\mathrm{Z}_{1-\beta}\right)^{2} \times\left(\left(\mathrm{P}_{1} \times\left(1-\mathrm{P}_{1}\right)+\mathrm{P}_{2} \times\left(1-\mathrm{P}_{2}\right)\right) /\left(\mathrm{P}_{1}-\mathrm{P}_{2}\right)^{2}\right.$

where:

$\mathrm{n}=$ Sample size

$Z_{1-\alpha / 2}=1.96$ when $\alpha=5 \%$ for two-sided test

$Z_{1-\beta}=0.842$ when $\beta=20 \%$ (test power $=80 \%$ )

$\mathrm{P}=$ Probability of the main outcome

\subsection{Participants}

The research hypothesis was a functional type hypothesis, and it was examined by devising a two-group, pretestposttest design of 86 subjects .The statistical population consists of women with orgasmic and arousal dysfunction problems who were referred to the psychiatric centers and psychological counseling offices at Kashan University of Medical Sciences. The non-probability sampling method was used, and the patients were divided into two groups of 43 people each, and they were assigned to treatment groups based on the randomization block permuted approach. During the study, three participants (two from the case group and one from the control group) were excluded due to the lack of follow-up of treatment. So, the study was performed on 83 patients.

\subsection{Selection criteria}

Inclusion criteria included a monogamous relationship with a man for at least six months prior to the study and the diagnosis of sexual performance disorders by a psychiatrist. Patients were excluded from the study if they had symptomatic heart disease, psychiatric problems, damage to the spinal cord, uncontrolled diabetes, drug use, alcohol consumption, brain stroke (at least six months prior to study), heart attack (at least six months before taking part in study), nitrate medication, physical health problems in the reproductive system detected by obstetricians. Also, we excluded women who were reluctant to have sexual relations due to family conflicts. 


\subsection{Outcomes and instruments}

The participants were assigned to the sildenafil and CBT groups based on the randomization block permuted approach. The outcomes of the study included measures of sexual function, sexual satisfaction, and marital satisfaction through three questionnaires before treatment began and 4, 8, and 12 weeks after the treatment was completed. The questionnaires were delivered by a female therapist, and, if the subjects were unable to complete the questionnaire, the therapist read the questions aloud to the patient and completed the questionnaire for the patient. To avoid obtaining biased information, the psychotherapist was unaware of the type of intervention the patient had. The questionnaires that we used were the following:

1) Female Sexual Function Index (FSFI) Questionnaire including nine items to evaluate women's sexual performance; the results were standardized using a Cronbach's alpha coefficient of 0.85 (21).

2) Sexual Satisfaction Questionnaire Form (for women): It is a an objective self-assessment tool to measure marital satisfaction with sex (gender barriers); it examined various related terms, such as sexual satisfaction, sexual shame, anxiety, sexuality, sexual health, sexual fears, and forced sexual relations between couples.

3) Marital Satisfaction Scale: An overall measurement of marital satisfaction, including inappropriate idealization in sexual function, marital satisfaction, personality problems, communication, conflict resolution, financial management, leisure activity, sex, children, parenting, family, friends, gender equality, religious orientation, marital solidarity, and marital conflicts of couples.

\subsection{Interventions}

After obtaining written informed consent, the patients were enrolled in the study. Demographic information, including information related to age, family size, socioeconomic status, education, and occupation, was collected through a questionnaire. Patients and their partners were examined by psychiatrists for the presence of sexual dysfunction in women. According to the information available, the criteria for inclusion or exclusion were evaluated, and inappropriate cases were excluded from study. Eligible candidates for inclusion in study were selected, and, after examining the exclusion criteria of the study, 83 patients were enrolled. The subjects in the sildenafil group were treated with $50 \mathrm{mg}$ of sildenafil one hour before having intercourse. The other group received weekly sessions of CBT for eight weeks by an experienced female who had her doctorate in clinical psychology. CBT sessions were performed according to the standard CBT protocol.

\subsection{Randomization and blinding}

In this clinical trial, stratified randomization was used with the baseline risk factor of the participants. For this, all participants were divided into two groups, i.e., those treated with sildenafil and those with treated with placebo. Randomization was done by one of researchers, who did not have a role in the treatment of the participants. The randomization sequence was computer-generated, with the randomization itself conducted through SPSS 20 software (SPSS, Inc., Chicago, IL, USA) (random number generation). We used variable block sizes of four and six for randomized sequence generation. Also, the allocation concealment was done by the researcher who was responsible for the randomization. After being allocated randomly to the groups, all participants were referred to the Hospital's pharmacy to get the sildenafil.

\subsection{Statistical methods}

After collecting the data, the results of the two groups in terms of arousal, orgasmic disorders, sexual satisfaction, and marital satisfaction were evaluated using paired t-tests and Wilcoxon tests. The groups were compared using ttests, Mann-Whitney, and covariance analysis. Data analysis was conducted using SPSS20 software (SPSS, Inc., Chicago, IL, USA). The two-tail value of $\mathrm{p}<0.05$ was considered as statistically significant. Also, before performing the statistical analyses, the normality of the variables' distribution was examined using the KolmogorovSmirnov test.

\subsection{Research ethics}

The proposal for this thesis research was presented to the Ethics Committee of Kashan University of Medical Sciences after its scientific approval by the Psychiatry Department. The Ethics Committee approved the study, and the enrollment of patients began on April 20, 2013. The study continued until April 20, 2014. Indeed, in this study, for ethical considerations, the participants were informed about the objective and nature of the study, and each participant provided her written consent in her native language (Persian) prior to the study. Also, we were committed to keeping all of the participants' information confidential. 


\section{Results}

In this study, 83 women with abnormal arousal and orgasm in both CBT and treatment group of sildenafil were studied. The mean age of the patients was $34.7 \pm 14.33$ years, with a minimum age of 20 and a maximum age of 44 . By comparing the two groups in terms of demographic characteristics of age, education, and occupation, no significant difference was observed, and both groups are relatively similar $(p>0.05)$. Demographic characteristics of patients are shown in Table 1. Comparing the two groups in terms of primary mean scores of sexual function, sexual satisfaction, and marital satisfaction showed similarities in terms of factors and prevalence of disorders at the beginning of study. This also was true in all of the following subscales. Comparison between sexual profiles of participants are shown in Table 2 and 3.

Table1. Demographic characteristics of patients based on treatment group

\begin{tabular}{|c|c|c|c|c|}
\hline \multirow{2}{*}{\multicolumn{2}{|c|}{ Characteristic }} & \multicolumn{2}{|l|}{ Group } & \multirow[t]{2}{*}{ p-value } \\
\hline & & Cognitive-behavioral therapy [n (\%)] & Sildenafil [n (\%)] & \\
\hline \multirow[t]{2}{*}{ Age groups (year) } & $\leq 34$ & $25(58.1)$ & $20(46.5)$ & \multirow[t]{2}{*}{0.028} \\
\hline & $>34$ & $18(41.9)$ & $23(53.5)$ & \\
\hline \multirow[t]{5}{*}{ Education } & Illiterate & $6(14)$ & $4(9.3)$ & \multirow[t]{5}{*}{0.063} \\
\hline & Elementary & $12(27.9)$ & $9(20.9)$ & \\
\hline & Guidance & $9(20.9)$ & $12(27.9)$ & \\
\hline & Diploma & $14(32.6)$ & $13(30.2)$ & \\
\hline & University & $2(4.7)$ & $5(11.6)$ & \\
\hline \multirow[t]{3}{*}{ Occupation } & Housekeeper & $33(76.7)$ & $31(72.1)$ & \multirow[t]{3}{*}{0.061} \\
\hline & Working & $6(14.0)$ & $5(11.6)$ & \\
\hline & Employee & $4(9.3)$ & $7(16.3)$ & \\
\hline
\end{tabular}

Table2. Comparison of the original score of patients in terms of sexual function, sexual satisfaction, and marital satisfaction

\begin{tabular}{|c|c|c|c|c|}
\hline \multirow{2}{*}{\multicolumn{2}{|c|}{ Scale }} & \multicolumn{2}{|l|}{ Group } & \multirow{3}{*}{$\begin{array}{l}\text { p-value } \\
0.731\end{array}$} \\
\hline & & CBT Mean (SD) & Sildenafil Mean (SD) & \\
\hline \multirow[t]{5}{*}{ Marital Satisfaction } & Sexual satisfaction & $73.19(18.76)$ & $71.88(16.19)$ & \\
\hline & Marital satisfaction & $29.53(5.85)$ & $29.63(5.2)$ & 0.938 \\
\hline & Communications & $27.39(3.56)$ & $26.77(4.32)$ & 0.464 \\
\hline & Resolve conflicts & $24.3(4.02)$ & $24.63(3.56)$ & 0.692 \\
\hline & Distortion of ideals & $14.6(4.08)$ & $13.79(2.28)$ & 0.369 \\
\hline \multirow[t]{6}{*}{ Sexual Function } & Desire & $3.06(1.27)$ & $2.89(1.12)$ & 0.501 \\
\hline & Mental stimulation & $2.07(1.17)$ & $2.13(1.14)$ & 0.823 \\
\hline & Lubrication & $2.09(1.38)$ & $2.25(14.3)$ & 0.586 \\
\hline & Orgasm & $1.29(0.97)$ & $1.54(0.9)$ & 0.217 \\
\hline & Satisfaction & $2.3(0.64)$ & $2.16(0.64)$ & 0.317 \\
\hline & Pain & $4.2(1.6)$ & $3.89(1.56)$ & 0.344 \\
\hline
\end{tabular}

Table 3. Comparison of sexual satisfaction scores in treatment groups during treatment

\begin{tabular}{|l|l|l|}
\hline \multirow{2}{*}{ Time interval } & Group & \\
\cline { 2 - 3 } & CBT Mean (SD) & Sildenafil Mean (SD) \\
\hline Before treatment & $73.19(18.76)$ & $71.88(16.19)$ \\
\hline After 4 weeks & $78.35(18.48)$ & $76.12(14.94)$ \\
\hline After 8 weeks & $83.67(19.16)$ & $77.65(15.2)$ \\
\hline After 12 weeks & $90.79(19.17)$ & $81.56(15.54)$ \\
\hline p-value & $<0.001$ & $<0.001$ \\
\hline
\end{tabular}

Based on the above results, the scale scores of sexual satisfaction in both treatment groups increased gradually. In CBT group, the score increased from 73.19, the baseline score, to 90.79 at the end of week $12(\mathrm{p}<0.001)$. In the sildenafil group, the baseline score of 71.88 increased to 81.56 over the same period of time $(p<0.001)$. Based on these results, both CBT and treatment with sildenafil increased the mean score related to the marital satisfaction subscales during the study period. This increase in the mean scores showed a significant difference at any stage with 
the previous one. In other words, both treatments improved sexual satisfaction. The mean score of marital satisfaction in cognitive-behavioral therapy group was increased from 29.53 at baseline to 38.37 , at the end of the week $12(\mathrm{p}<0.001)$. Results of sexual satisfaction and sexual function after treatment are shown in Table 4 and 5. The same number in the sildenafil group was 29.63, which increased to $36.02(\mathrm{p}<0.001)$.

The mean score of communication in cognitive-behavioral therapy group was 27.4 at the start of treatment, and it reached 36.93 at the end of the week $12(\mathrm{p}<0.001)$. This number in the sildenafil treatment group was 26.76, and it increased to $31.05(\mathrm{p}<0.001)$. The mean score of cognitive conflict resolution in the cognitive-behavioral group, which was 24.3 at baseline, was increased to 31.98 at the end of week $12(p<0.001)$. The same number of 24.63 in those who received the sildenafil treatment reached $29.88(\mathrm{p}<0.001)$. The cognitive-behavioral group therapy's inappropriate idealization mean score of 14.6 at baseline was increased to $18.37(\mathrm{p}<0.001)$ at the end of week 12 , and it increased from 13.79 to 17.25 in the sildenafil treatment group $(\mathrm{p}<0.001)$. Follow up of the sexual function in women showed a gradual increase in their scores during treatment. Therefore, the score of sex derive (desire) was increased from 3.06 to 4.54 at the end of week $12(p<0.001)$. In the sildenafil group the number increased from 2.89 to 3.97 ( $<<0.001$ ). The arousal scored increased from 2.07 to 3.82 at the end week 12 of treatment $(\mathrm{p}<0.001)$. The arousal score of the sildenafil group increased from 2.13 to $3.97(\mathrm{p}<0.001)$. The lubrication score of 2.08 at baseline was increased to 3.7 at the end of the week $12(\mathrm{p}<0.001)$. In the sildenafil group, this number increased from 2.25 to $4.25(\mathrm{p}<0.001)$. The orgasm score of 1.29 at the beginning of study reached 2.86 at the end of week 12 $(\mathrm{p}<0.001)$. In the sildenafil group, this score increased from 1.54 to $3.39(\mathrm{p}<0.001)$. The sexual satisfaction score of 2.3 at baseline reached 3.71 at the end of week $12(\mathrm{p}<0.001)$. In the sildenafil group, the score increased from 2.16 to 3.2 ( $\mathrm{p}<0.001)$. Reduction in pain score increased from 4.21 to 4.91 at the end of week $12(\mathrm{p}<0.001)$, whereas it increased from 3.89 to 4.67 in the sildenafil group $(\mathrm{p}<0.001)$.

Table4. Comparison of the mean score of marital satisfaction during treatment sessions in each group

\begin{tabular}{|l|l|l|l|}
\hline Subscale & Time & Group & \\
\cline { 2 - 4 } & & CBT Mean (SD) & Sildenafil Mean (SD) \\
\hline Marital Satisfaction & Before treatment & $29.53(5.85)$ & $29.63(5.2)$ \\
\cline { 2 - 4 } & 4 weeks & $31.74(6.0)$ & $30.9(5.21)$ \\
\cline { 2 - 4 } & 8weeks & $33.41(5.99)$ & $31.88(4.85)$ \\
\cline { 2 - 4 } & 12 weeks & $38.37(6.01)$ & $36.02(4.85)$ \\
\cline { 2 - 4 } & p-value & $<0.001$ & $<0.001$ \\
\hline Communications & Before treatment & $27.4(3.56)$ & $26.76(4.32)$ \\
\cline { 2 - 4 } & 4weeks & $29.07(3.78)$ & $28.32(4.46)$ \\
\cline { 2 - 4 } & 8weeks & $34.28(5.13)$ & $29.72(4.98)$ \\
\cline { 2 - 4 } & 12 weeks & $36.93(5.03)$ & $31.05(5.63)$ \\
\cline { 2 - 4 } & p-value & $<0.001$ & $<0.001$ \\
\hline Donflict resolution & Before treatment & $24.3(4.02)$ & $24.63(3.56)$ \\
\cline { 2 - 4 } & 4 weeks & $26.98(4.68)$ & $25.53(3.6)$ \\
\cline { 2 - 4 } & 8weeks & $30.05(4.81)$ & $27.3(3.6)$ \\
\cline { 2 - 4 } & 12 weeks & $31.98(4.69)$ & $29.88(3.87)$ \\
\cline { 2 - 4 } & p-value & $<0.001$ & $<0.001$ \\
\hline & Before treatment & $14.6(4.4 .08)$ & $13.79(4.28)$ \\
\cline { 2 - 4 } & 4weeks & $15.77(4.07)$ & $14.7(4.5)$ \\
\cline { 2 - 4 } & 8weeks & $16.77(4.18)$ & $15.67(4.66)$ \\
\cline { 2 - 4 } & 12 weeks & $18.37(3.75)$ & $17.25(3.73)$ \\
\cline { 2 - 4 } & p-value & $<0.001$ & $<0.001$ \\
\hline
\end{tabular}


Table 5. Comparison of sexual function scores in treatment groups during treatment

\begin{tabular}{|c|c|c|c|}
\hline \multirow[t]{2}{*}{ Subscale } & \multirow[t]{2}{*}{ Time } & \multicolumn{2}{|l|}{ Group } \\
\hline & & CBT Mean (SD) & Sildenafil Mean (SD) \\
\hline \multirow[t]{5}{*}{ Desire } & Before treatment & $3.06(1.27)$ & $2.89(1.12)$ \\
\hline & 4 weeks & $3.59(1.44)$ & $3.32(1.26)$ \\
\hline & 8 weeks & $3.88(1.43)$ & $3.6(1.33)$ \\
\hline & 12 weeks & $4.54(1.29)$ & $3.9(1.39)$ \\
\hline & p-value & $<0.001$ & $<0.001$ \\
\hline \multirow[t]{5}{*}{ Arousal } & Before treatment & $2.07(1.17)$ & $2.13(1.14)$ \\
\hline & 4 weeks & $2.7(1.1)$ & $3.24(1.09)$ \\
\hline & 8 weeks & $3.03(1.14)$ & $3.86(1.18)$ \\
\hline & 12 weeks & $3.28(1.12)$ & $3.97(1.21)$ \\
\hline & p-value & $<0.001$ & $<0.001$ \\
\hline \multirow[t]{5}{*}{ Lubrication } & Before treatment & $2.08(1.38)$ & $2.25(1.24)$ \\
\hline & 4 weeks & $1.66(1.4)$ & $2.96(1.17)$ \\
\hline & 8 weeks & $3.9(1.34)$ & $3.75(0.98)$ \\
\hline & 12 weeks & $3.7(1.35)$ & $4.25(0.94)$ \\
\hline & p-value & $<0.001$ & $<0.001$ \\
\hline \multirow[t]{5}{*}{ Orgasm } & Before treatment & $1.29(0.97)$ & $1.54(0.9)$ \\
\hline & 4 weeks & $1.62(0.98)$ & $2.43(1.02)$ \\
\hline & 8 weeks & $2.04(1.14)$ & $3.02(1.12)$ \\
\hline & 12 weeks & $2.86(1.09)$ & $3.39(1.19)$ \\
\hline & p-value & $<0.001$ & $<0.001$ \\
\hline \multirow[t]{5}{*}{ Satisfaction } & Before treatment & $2.3(0.64)$ & $2.16(0.64)$ \\
\hline & 4 weeks & $2.65(0.77)$ & $2.58(0.77)$ \\
\hline & 8 weeks & $3.27(0.9)$ & $3.01(0.86)$ \\
\hline & 12 weeks & $3.71(0.98)$ & $3.2(0.94)$ \\
\hline & $\mathrm{p}$-value & $<0.001$ & $<0.001$ \\
\hline \multirow[t]{5}{*}{ Pain } & Before treatment & $4.21(1.61)$ & $3.89(1.56)$ \\
\hline & 4 weeks & $4.54(1.5)$ & $4.16(1.48)$ \\
\hline & 8weeks & $4.72(1.45)$ & $4.45(1.49)$ \\
\hline & 12 weeks & $4.91(1.35)$ & $4.67(1.42)$ \\
\hline & $\mathrm{p}$-value & & \\
\hline
\end{tabular}

\section{Discussion}

Sexual desire has an undeniable impact on quality of life of a person and her/his sexual partner. This resulted in the inclusion of sexual dysfunction in psychiatric disorders and classifying it as a disorder in axis I (22). Different factors affect sexual desire, performance, and human sexuality, and they include physiological, anatomical, psychological, and socio-cultural factors. Personal developmental experiences from childhood to adulthood, relationships with others, and the formation of one's personality all have important roles in the coherence of gender identity and sexual orientation (23). Sexual dysfunction presents itself as a lack of sexual desire, arousal, sexual stimulation disorder, orgasmic disorders, and pain. Its development involves psychological, physiological, and medical factors and often a combination of all three (24).

In this study, 83 women with abnormal arousal and orgasmic problems in both CBT and treatment groups with sildenafil were studied. The mean age of the patients was $33.14 \pm 7.34$, the minimum age was 20 , and the maximum age was 44. Previous studies have pointed to the high prevalence of PTSD among women. In the United States, for example, the highest incidence of disorder with approximately $23-63 \%$ is reported in age group of post-menopause women (25). A study by Safarinejad and colleagues on a group of Iranian women found the overall prevalence of sexual dysfunction to be $31.5 \%$, while the prevalence of sexual desire disorder was $35 \%$, arousal disorder $30 \%$, prevalence of dyspareunia $26.7 \%$, and orgasmic disorder with $37 \%$, respectively (24). A study conducted at the national level on individuals between the ages of 18 and 59 showed that sexual dysfunction is common in women, and it was observed in $43 \%$ of the participants (26). 
Significant differences in the prevalence of female sexual dysfunction (FSD) in various populations may reflect medical and psychological factors, especially in the field of social, economic, cultural, and racial differences, differences in clinical definitions used for description of disorders, the questionnaire used in study (such as selfassessment questionnaires, telephone interviews, personal interviews), type of relationship with sex partner, level of education and the characteristics of study sample (general public compared with people referring to sex clinics).

Nitric oxide can be used as a dilator of vascular smooth muscle in cavernous body of clitoris and have vaginal muscle relaxant effects and, by a mechanism similar to that seen in men with erectile dysfunction, it also may prove effective in the treatment of women suffering from sexual dysfunction (27). Unlike treatment of male sexual dysfunction, in addressing the female sexual dysfunction there is the problem of lack of drug therapies. Today, the only medical treatments available take a long time to respond, and that is not always associated with satisfaction and compliance on part of patients. In addition, especially those who suffer from severe sexual dysfunction, may reject such treatments. This can be caused due to various physiological factors or deeper personality disorders in such patients. In such circumstances, CBT appears to be a more appropriate option. Although there are many reports on the success of this treatment, some specific types of sexual dysfunction exist in women that are resistant to all existing treatments (25).

Sexual dysfunction in women may be secondary to some endocrine disorders. Accordingly, hormone therapy, such as the use of testosterone replacement, is sometimes used in treatment of these disorders $(28,29)$. Also, there are other studies that have benefited from medicines to treat sexual function problems $(30,31)$.

In this study, the efficacy of sildenafil therapy and cognitive behavior therapy on excitement disorders, orgasm, sexual satisfaction, and marital satisfaction in women was compared. Several studies have been conducted in these areas; however, conflicting results have been reported. The results of this study showed that treatment with sildenafil decreased the rate of sexual dysfunction in all aspects of the study, such as marital satisfaction, sexual satisfaction, and sexual performance. Although several studies have been conducted in this area, conflicting results have been reported.

One of the first clinical trials on the effects of sildenafil on women was done by Sipski and colleagues in 2000. In this study, 19 premenopausal women with spinal cord injuries in the sacral region of the spinal cord were examined. Participants were divided into two groups: one group received sildenafil citrate, and the second group was given a placebo. In this study, it was found that vaginal pulse amplitude (which was measured by vaginal photoplethysmography) in patients receiving sildenafil was increased significantly. Also, patients who received sildenafil reported higher degrees of sexual arousal. It was also noted that the recipients of sildenafil had an increased heart rate of 4-5 beats per minute and a higher blood pressure of 2-4 mm during sexual arousal than control group participants. This study was the first to examine cardiovascular effects of sildenafil citrate in women during sexual arousal (32).

A 2001 study conducted on 53 women before menopause by Caruso et al. showed that both 25 - and 50-mg doses of sildenafil were effective in the women, and they generally reported an improvement in the quality of their married life (33). In one study in 2003, Caruso and colleagues worked on the effect of sildenafil in women with sexual dysfunction that were free of any disease and reported their improved arousal, orgasm, and sexual satisfaction compared to the placebo group (34). In a similar study conducted by Berman et al., the effects of sildenafil on sexual dysfunction in postmenopausal women were examined, and it was found that sildenafil improved the condition of patients in terms of their sexual desire and arousal (35). Positive, but average, effects of sildenafil were noted in a study by Schoen and colleagues (36). In contradiction with the results of mentioned studies, some studies have pointed out that sildenafil has very little effect or is ineffective in the treatment of female sexual dysfunction. Laan et al., in a 2002 study, reported that, although vaginal pulse amplitude was increased after receiving sildenafil, the participants did not mention any difference between wet vagina and sexual arousal after receiving the drug $(37,38)$. Kaplan et al., in their study, reported only lubrication changes in vaginal and clitoral sensitivity in patients treated with sildenafil (39). Alexander and colleagues did a comparison between the effects of sildenafil and placebo and concluded that the drug had no clinically-significant effect (40). When examining the effects of sildenafil on female sexual functionally, it was found that sildenafil may increase congestion of the vagina, but it has no effect on excitement (23). This difference in results can be attributed to the manner and extent of drug administration, assessment of sexual status, and cultural status of the subjects in the study. Moreover, in most studies, the sample size has been very small, which makes their validity questionable. 
In this study, it was found that cognitive-behavioral therapy in women with sexual dysfunction may improve sexual satisfaction, marital satisfaction, and sexual performance in all subscales under question. Effectiveness of cognitivebehavioral therapy in treatment of sexual problems in females has been examined in different studies, and various aspects of sexual dysfunction have been addressed. Libman and colleagues compared various methods of treatment for female orgasmic disorder and found that CBT is effective in this disorder (41). Ter Kuile and colleagues, by conducting a cognitive behavioral treatment period of three months for women with vaginismus and then comparing them with the control group, observed a reduced severity of disorder during the treatment time and better performance of subjects under treatment than those in the control group (42). Jabari and colleagues, in their study of six women with sexual anxiety, performed cognitive-behavioral therapy for 3 months, and found that these patients had a significant improvement regarding their sexual function than those who were treated only with the behavioral approach (43). Although most studies on the effects of cognitive behavior therapy on sexual disorders, such as studies of sildenafil, are not credible due to their small sample size, but, to date, none of these studies has questioned the effectiveness of cognitive-behavioral therapy in the treatment of female sexual dysfunction.

In this study, it was found that cognitive-behavioral therapy, compared with treatment with Sildenafil, outperformed the second method in every aspect except for sexual excitement, lubrication, and better performance. This proved that this approach was more effective in the treatment of female sexual arousal and orgasm disorders. To date, no study has been conducted to compare the effectiveness of these methods. The current study confirmed that mental processes have a stronger role than physiological factors. Negative thinking about sexual activity makes symptoms of disorder constant and aggravated. Therefore, discovery of the negative self-dictations helps in successful analysis of sexual problems. However, drug treatment only influences purely physiological disorders, which are the result of mentally-defective processes, so it only targets the subject and not the main cause. Thus, its efficacy is less than that of cognitive-behavioral therapies. Side effects and limitation of prescription of drugs, such as sildenafil, for sexual disorder treatment, together with its' doubtful effectiveness, makes CBT therapy a good choice, although further studies are necessary.

\section{Conclusions}

This study found that sildenafil was more effective in treating female sexual dysfunction, difficulties in creating and maintaining excitement and lubrication, and orgasm disorders than cognitive-behavioral therapy. The difference was statistically significant, although the cognitive-behavioral therapy seemed to be more influential in terms of increased levels of sexual satisfaction and marital satisfaction. However, other aspects of sexual activity, such as sex drive and pain, were decreased in comparison with sildenafil therapy, and, once again, there were significant differences between the two methods. Our recommendations for future research are: 1) design and implement community-wide studies to evaluate the effect of sildenafil in the treatment of female sexual dysfunction; 2) design and implement studies to evaluate the effect of sildenafil on sexual satisfaction and marital satisfaction; 3) design and implement further studies of the effects of sildenafil therapy and the cognitive-behavioral approach on sexual satisfaction and marital satisfaction to better understand the preferred method of treatment for these disorders; and 4) design and implement further studies about the effects of sildenafil therapy and the cognitive-behavioral approach on the level of sexual satisfaction and marital satisfaction.

\section{Acknowledgments:}

This paper was extracted from a Psychiatry residency thesis at Kashan University of Medical Sciences. The authors appreciate the assistance and cooperation provided by the staff members in the Psychiatry Department, and we sincerely appreciate all of the women who participated in the study.

\section{Clinical trial registration:}

The trial was registered at the Iranian Registry of Clinical Trials (http://www.irct.ir) with the IRCT ID: IRCT2014070318338N1.

\section{Funding:}

The authors received no financial support for the research, authorship, and/or publication of this article.

\section{Conflict of Interest:}

There is no conflict of interest to be declared. 


\section{Authors' contributions:}

All authors contributed to this project and article equally. All authors read and approved the final manuscript.

\section{References}

1) Walton B, Thorton T. Female sexual dysfunction. Curr Womens Health Rep. 2003; 3: 319-26. PMID: 12844457.

2) Marita McCabe, Althof SE, Assalian P, Chevret-Measson M, Leiblum SR, Simonelli C. et al.. Psychological and interpersonal Dimensions of sexual function and dysfunction. 2010; 7(1 Pt 2): 327-36. doi: 10.1111/j.1743-6109.2009.01618.x, PMID: 20092442.

3) Sarrel P, Dobay B, Wiita B. Estrogen and estrogen-androgen replacement in postmenopausal women dissatisfied with estrogen only therapy. Sexual behavior and neuroendocrine responses. J Reprod Med. 1998; 43(10): 847-56. PMID: 9800666.

4) Sprecher S. Sexual satisfaction in premarital relationship: Associations with satisfaction, love, commitment, and stability. J Sex Res. 2002; 39: 190. doi: 10.1080/00224490209552141, PMID: 12476266.

5) Nicolosi A, Moreira ED, Villa M, Glasser DB. A population study of the association between sexual function, sexual satisfaction, and depressive symptoms in men. J Affect Disord. 2004; 82: 235-43. doi: 10.1016/j.jad.2003.12.008, PMID: 15488252.

6) Jahanfar Sh, Molay Nejad M. Sexual disorders. 1st ed Tehran: Bijeh Publication. 2002: 150-4 (Persian).

7) Litzinger S, Gordon KC. Exploring relationships among communication, sexual satisfaction, and marital satisfaction. J Sex Mar Therap. 2005; 31: 409-24. doi: 10.1080/00926230591006719, PMID: 16169824.

8) Greenberg J, Brues C, Heffner D. Exploring the dimension of human sexuality. Boston: Janes \& Bartlet; 2002.

9) Dunn KM, Croft P. Satisfaction in the sex life of a general population sample. J Sex Marital Ther. 2000; 26(2): 141-51. PMID: 10782446.

10) Abbasi F. Relationship between sexual function andsatisfaction of married women with mental health of Qazvin [dissertation]. Tehran Iran: Iran University of Medical Sciences; 2006.

11) Nabipoor A. Effect on increasing sexual skills and marital satisfaction [dissertation]. Tehran Iran: Azad University; 2005.

12) Ali-Akbari M, Kayghobadi S. Sexual relationship with mental health and marital adjustment of women referred to the Tehran Psychiatric Institute. Tehran; Proceedings ofthe Fourth Global Congress on Family and Sexual Health; 2009.

13) Sadeghi F. Exploring socio-psychological causes of divorce in Iran. [MAthesis]. Tehran Iran: Tehran University; 1997.

14) Araoz D. Hypnosis in Human Sexuality Problems, Am J Clin Hypn. 2005; 47: 229-42. doi: 10.1080/00029157.2005.10403637, PMID: 15915850.

15) Brotto YE, Erskine Y, Carey M, Ehlen T, Finlayson S, Heywood M, et al. A brief mindfulness-based cognitive behavioral intervention improves sexual functioning versus wait-list control in women treated for gyneocologic cancer. Gynecol Oncol. 2012; 320-325. doi: 10.1016/j.ygyno.2012.01.035, PMID: 22293042, PMCID: PMC3438201.

16) Stefan G Hofmann, Asnaani A, Vonk IJJ, Sawyer AT, Fang A. The efficacy of cognitive behavioral therapy: A review of meta analyses. 2012; 36(5): 427-40. PMCID: PMC3584580.

17) Stephenson KR, Rellini AH, Meston CM . Relationship Satisfaction as a predictor of treatment response during cognitive behavioral sex therapy. Arch Sex Behav. 2013; 42(1): 143-52. doi: 10.1007/s10508-0129961-3, PMID: 22588577.

18) Meston CM, Hull E, Levin RJ, Sipski M. Disorders of orgasm in women. J Sex Med. 2004; 1(1): 66-8. doi: 10.1111/j.1743-6109.2004.10110.x, PMID: 16422985.

19) Zolfaghari M. The efficacy of cognitive behavioral therapy on women sexual disfunction [dissertation]. Esfahan Iran: Esfahan University of Medical Sciences; 2006

20) Boolell M, Gepi-Attee S, Gingell JC, Allen MJ. Sildenafil, a novel effective oral therapy for male erectile dysfunction. Br J Urol. 1997; 79: 663-4. PMID: 8813924.

21) Ghassamia M, Asghari A, Shaeiri MR, Safarinejad MR. Validation of psychometric properties of the Persian version of the Female Sexual Function Index. Urol J. 2013; 10(2): 878-85. PMID: 23801471.

22) Sadock BJ, Kaplan HI, Sadock VA. Kaplan and Sadock comprehensive textbook of psychiatry. Philadelphia, USALippincott Williams \& Wilkins; 2009: 732-40.

23) Chivers M, Rosen RC. Phosphodiesterase type 5 inhibitors and female sexual response: faulty protocols paradigms? J sex med. 2010; 7: 858-72. doi: 10.1111/j.1743-6109.2009.01599.x, PMID: 19929916. 
24) Safarinejad MR. Female sexual dysfunction in a population-based study in Iran: prevalence and associated risk factors. Int J Impot Res. 2006; 18: 382-95. PMID: 16395324.

25) McCabe MP. Evaluation of a cognitive behavior therapy program for people with sexual dysfunction. J Sex Marital Ther. 2001; 27(3): 259-71. doi: 10.1080/009262301750257119, PMID: 11354931.

26) Tuiten A, Van Honk J, Koppeschaar H, Bernaards C, Thijssen J, Verbaten R. Time course of effects of testosterone administration on sexual arousal in women. Arch Gen Psychiatry. 2000; 57: 149-53. doi: 10.1001/archpsyc.57.2.149, PMID: 10665617.

27) Cavalcanti AL, Bagnoli VR, Fonseca AM, Pastore RA, Cardoso EB, Paixão JS, et al. Effect of sildenafil on clitoral blood flow and sexual response in postmenopausal women with orgasmic dysfunction. Int J Gynaecol Obstet. 2008; 102(2): 115-9. doi: 10.1016/j.ijgo.2008.03.020, PMID: 18589423.

28) Sarrel P, Dobay B, Wiita B. Estrogen and estrogen-androgen replacement in postmenopausal women dissatisfied with estrogen only therapy. Sexual behavior and neuroendocrine responses. J Reprod Med. 1998; 43(10): 847-56. PMID: 9800666.

29) Jaafarpour M, Khani A, Khajavikhan J, Suhrabi Z. Female sexual dysfunction: prevalence and risk factors. J Clin Diagn Res. 2013; 7(12): 2877-80.

30) Nurnberg HG, Levine PE: Spontaneous remission of MAOI-induced anorgasmia. Am J Psychiatry. 1987; 144: 805-7. doi: 10.1176/ajp.144.6.805, PMID: 3592004.

31) Michelson D, Bancroft J, Targum S, Kim Y, Tepner R. Female sexual dysfunction associated with antidepressant administration: a randomized, placebo-controlled study of pharmacologic intervention. Am J Psychiatry. 2000; 157: 239-43. doi: 10.1176/appi.ajp.157.2.239, PMID: 10671393.

32) Sipski ML, Rosen RC, Alexander CJ, Hamer RM. Sildenafil effects on sexual and cardiovascular responses in women with spinal cord injury. Urology. 2000; 55(6): 812-5. doi: 10.1016/S0090-4295(00)00493-3.

33) Caruso S, Intelisano G, Lupo L, Agnello C. Premenopausal women affected by sexual arousal disorder treated with sildenafil: a double-blind, cross-over, placebo-controlled study. BJOG. 2001; 108(6): 623-8. doi: 10.1111/j.1471-0528.2001.00143.x, PMID: 11426898.

34) Caruso S, Intelisano G, Farina M, Di Mari L, Agnello C. The function of sildenafil on female sexual pathways: a double-blind, cross-over, placebo-controlled study. Eur J Obstet Gynecol Reprod Biol. 2003; 110(2): 201-6. doi: 10.1016/S0301-2115(03)00118-0, PMID: 12969584.

35) Berman JR, Berman LA, Toler SM, Gill J, Haughie S; Sildenafil Study Group. Safety and efficacy of sildenafil citrate for the treatment of female sexual arousal disorder: a double-blind, placebo controlled study. J Urol. 2003; 170(6 Pt 1): 2333-8. doi: 10.1097/01.ju.0000090966.74607.34, PMID: 14634409.

36) Schoen C, Bachmann G. Sildenafil citrate for female sexual arousal disorder: a future possibility? Nat Rev Urol. 2009; 6(4): 216-22. doi: 10.1038/nrurol.2009.25, PMID: 19352396.

37) Laan E, van Lunsen RH, Everaerd W, Riley A, Scott E, Boolell M. The enhancement of vaginal vasocongestion by sildenafil in healthy premenopausal women. J Womens Health Gend Based Med. 2002; 11(4): 357-65. doi: 10.1089/152460902317585994, PMID: 12150498.

38) Laan E, van Lunsen RH, Everaerd W, Riley A, Scott E, Boolell M. The enhancement of vaginal vasocongestion by sildenafil in healthy premenopausal women. J Womens Health Gend Based Med. 2002; 11(4): 357-65. doi: 10.1089/152460902317585994, PMID: 12150498.

39) Kaplan SA, Reis RB, Kohn IJ, Ikeguchi EF, Laor E, Te AE, et al. Safety and efficacy of sildenafil in postmenopausal women with sexual dysfunction. Urology. 1999; 53(3): 481-6. doi: 10.1016/S00904295(98)00633-5, PMID: 10096370.

40) Alexander MS, Rosen RC, Steinberg S, Symonds T, Haughie S, Hultling C. Sildenafil in women with sexual arousal disorder following spinal cord injury. Spinal Cord. 2011; 49(2): 273-9. doi: 10.1038/sc.2010.107, PMID: 20733587.

41) Libman E, Fichten CS, Brender W, Burstein R, Cohen J, Binik YM. A comparison of three therapeutic formats in the treatment of secondary orgasmic dysfunction. J Sex Marital Ther. 1984; 10(3): 147-59. doi: 10.1080/00926238408405940, PMID: 6512867.

42) TerKuile MM, van Lankveld JJ, de Groot E, Melles R, Neffs J, Zandbergen M. Cognitive-behavioral therapy for women with lifelong vaginismus: process and prognostic factors. Behav Res Ther. 2007; 45(2): 359-73. doi: 10.1016/j.brat.2006.03.013, PMID: 16701078 .

43) Jaberi P, Mehrabi F, Mehryar H. Psychosocial Factors in Patients with Duodenal Ulcer. IJPCP. 1999; 5(1 and 2):79-92. 